\title{
Development of IDF Curve for Dhaka City Based on Scaling Theory under Future Precipitation Variability Due to Climate Change
}

\author{
S. Afrin, M. M. Islam, and M. M. Rahman
}

\begin{abstract}
Bangladesh is one of the most vulnerable countries of the world to climate change. The magnitude and frequency of extreme events such as high intensity rainfall, flash flooding, severe droughts, etc. are expected to be altered in future as a consequence of this change. This can introduce an element of uncertainty in the design of hydraulic structures, urban drainage systems, and other water-sensitive structures, if the variability is not taken into consideration. This study aims at developing a regional Intensity-Duration-Frequency (IDF) relationship for Dhaka city for present as well as future climatic scenarios. The scaling properties of extreme rainfall are examined to establish scaling relationship behavior of statistical moments over different durations. The results show that a rainfall property in time does follow a simple scaling process. A scale invariance concept is explored for disaggregation (or downscaling) of rainfall intensity from low to high resolution and is applied to the derivation of scaling IDF curves. These curves are developed based on scaling of the generalized extreme value (GEV) and Gumbel probability distributions. It is seen that scaled estimates are relatively close to observed estimates.
\end{abstract}

Index Terms-Climate change, extreme values, IDF curves, scaling exponent, simple scaling.

\section{INTRODUCTION}

Dhaka, the capital city of Bangladesh and one of the fastest growing mega cities in the world, is continuously changing due to rapid and unplanned urbanization. It is subjected to annual average rainfall of 2,076 $\mathrm{mm}$ of which almost $80 \%$ falls during the monsoon [1]. Consequently, Dhaka metropolitan area has experienced water logging for last couple of years. In September 11th to 16th, 2004 heaviest ever rainfall $(341 \mathrm{~mm})$ occurred in Dhaka City and its devastating impact paralyzed the city life. Hence the study of extreme rainfall events in Dhaka is a major interest to water engineering professionals. Such information is often expressed as a relationship between rainfall intensity, duration and frequency of occurrence (probability or return period in years). These relationships are known as IDF curves or equations and are usually derived using observed annual maximum (AM) series. IDF relationships are usually available in graphical form as well as in equation [2]. In developing IDF relationships, the estimates of rainfall intensity for a given duration and frequency can be obtained

Manuscript received May 26, 2014; revised August 4, 2014.

The authors are with the Department of Civil Engineering, Bangladesh University of Engineering and Technology (BUET), Dhaka-1000, Bangladesh (e-mail: sadiaafrinbuet@gmail.com, maksimulislam075@gmail.com, mujib@ce.buet.ac.bd). from statistical analysis employing Gumbel probability distributions and parameter estimation methods (such as method of moments) [3]. There is much discussion in the literature [4] about the various approaches for statistical analysis of extreme values which are not explored here.

IDF relationships are used in the design, construction, and management of many water resources projects involving natural hazards due to extreme rainfall events. In the absence of adequate stream flow data, rainfall data is used extensively in the synthesis of peak flows. It is therefore very important to have reliable estimates of IDF relationships which can reflect present as well as possible future conditions.

The variable nature of precipitation in Bangladesh makes it difficult to discern trends in the observed record. However, an increase of $4.26 \%$ was observed in the percent difference between the total annual precipitation (average of 34 meteorological station-data) of the past 20 years (1953-1972) and the recent 20 years on record (1985-2004) which represents that the annual rainfall follows an increasing trend [5]. Reference [6] also showed that trend of annual daily maximum rainfall for the last 30 years (1979 to 2009) showed an increase of $2.7 \mathrm{~mm}$ per year.

Also, the precipitation might continue to increase in all the months in future years. Percentage of precipitation increment is expected to be quite higher for dry and pre-monsoon months compared to the monsoon season. Also, the large scatters in the projected precipitation quantities of July and in most other monsoon months are expected, indicating that there will be years with more or less rainfall with significant fluctuations from average conditions [5]. According to the third assessment report of Intergovernmental Panel on Climate Change [7], developing countries are expected to suffer the most from the negative impacts of climate change. Changes in rainfall pattern are likely to lead to severe water shortages and flooding. The IPCC Special Report on the Regional Impacts of Climate Change [8] indicates that there would be drastic changes in the rainfall patterns in the warmer climate and Bangladesh may experience 5-6\% increase of rainfall by 2030 , which may create frequent massive and prolonged floods.

Until now, some IDF relationships have been developed for Dhaka city while equations incorporating future climate scenarios have not been developed yet. IDF relationships, which are developed without examining whether rainfall events are subject to climate change, may give rise to many uncertainties. Thus, in this paper, IDF relationships are developed using projected future precipitation data and validated with respect to present data. 


\section{Simple SCALing CHARACTERISTICS OF RAINFALL}

In this section, a general theoretical framework for the simple scaling is introduced. The scaling or scale-invariant models enable us to transform data from one temporal or spatial model to another one, and thus, help to overcome the difficulty of inadequate data. A natural process fulfills the simple scaling property if the underlying probability distribution of some physical measurements at one scale is identical to the distribution at another scale, multiplied by a factor that is a power function of the ratio of the two scales. The basic theoretical development of scaling has been investigated by many authors [9], [10].

Let $X(t)$ and $X(\lambda t)$ denote measurements at two distinct time or spatial scales $t$ and $\lambda t$, respectively. Definition of scaling of the probability of the $X(t)$ is

$$
X(t)=\lambda^{-H} X(\lambda t)
$$

where $\lambda$ denotes a scale factor and $H$ is a scaling exponent which varies with location. Gupta and Waymire1) introduced the notions of strict and wide sense simple scaling. The strict sense simple scaling in Eq. (1) implies that $X(t)^{q}$ and $\left(\lambda^{-H} X(\lambda t)\right)^{q}$ have the same probability distribution. The wide sense simple scaling is expressed as they have the same moments, i.e.

$$
E\left[X(t)^{q}\right]=\lambda^{-H q} E\left[X(\lambda t)^{q}\right]
$$

The scaling exponent $(H q)$ can be estimated from the slope of linear regression relationship between the $\log$ transformed values of moment, $\log E\left[X(\lambda t)^{q}\right]$ and scale parameters $\log \lambda$ for various order of moment $q$. This is definition of a "wide sense" simple scaling. A "wide sense" simple scaling with $t=1$ is given by

$$
E\left[X(1)^{q}\right]=\lambda^{-H q} E\left[X(\lambda)^{q}\right]
$$

If the scaling exponent $H$ is not constant and changes probabilistically, equation (3) are described as

$$
E\left[X(1)^{q}\right]=\lambda^{-K(q)} E\left[X(\lambda)^{q}\right]
$$

where $K(q)$ is a function of the moment order. The procedure to test the suitability of scale invariant model to describe the rainfall process is shown in Fig. 1. The moments $E\left[X(\lambda t)^{q}\right]$ are plotted on the logarithmic chart versus the scale $\lambda$ for different moments' order $q$. The slope $K(q)$ is plotted on the linear chart versus the moment order $q$. If the resulting graph is a straight line, the field is simple scaling, while in other cases, the multi-scaling approach has to be considered. Let the random variable $I(d)$, the maximum annual value of local rainfall intensity over a duration $d$. It is defined as:

$$
I(d)=\max _{0 \leq t \leq 1 \text { year }}\left[\frac{1}{d} \int_{t-d / 2}^{t+d / 2} X(\xi) d \xi\right]
$$

where $X(\xi)$ is a time continuous stochastic process representing rainfall intensity and $d$ is duration. It is supposed that $I(d)$ represents the Annual Maximum Rainfall Intensity (AMRI) of duration $d$, defined by the maximum value of moving average of width $d$ of the continuous rainfall process.
Here, some concepts are introduced about scaling of the probability distribution of random functions. A generic random function $I(d)$ is denoted by simple scaling properties if it obeys the following:

$$
I(d)=\left(\frac{D}{d}\right)^{-H_{d}} I(D)
$$

$D$ is a aggregated time duration, i.e.: $2,3, \ldots, 24$ hours.

Defining the scaling ratio is $\lambda_{d}=\frac{D}{d}$

$$
I(d)=\lambda_{d}{ }^{-H_{d}} I\left(\lambda_{d} d\right)
$$

The Eq. (7) is rewritten in terms of the moments of order $q$ about the origin, denoted by $E\left[I(d)^{q}\right]$.

The resulting expression is:

$$
E\left[I(d)^{q}\right]=\lambda_{d}{ }^{-H_{d} q} E\left[I\left(\lambda_{d} d\right)^{q}\right.
$$

If one assumes the wide sense simple scaling exists, the distribution of IDF for short-duration of rainfall intensity can be derived from daily rainfall.

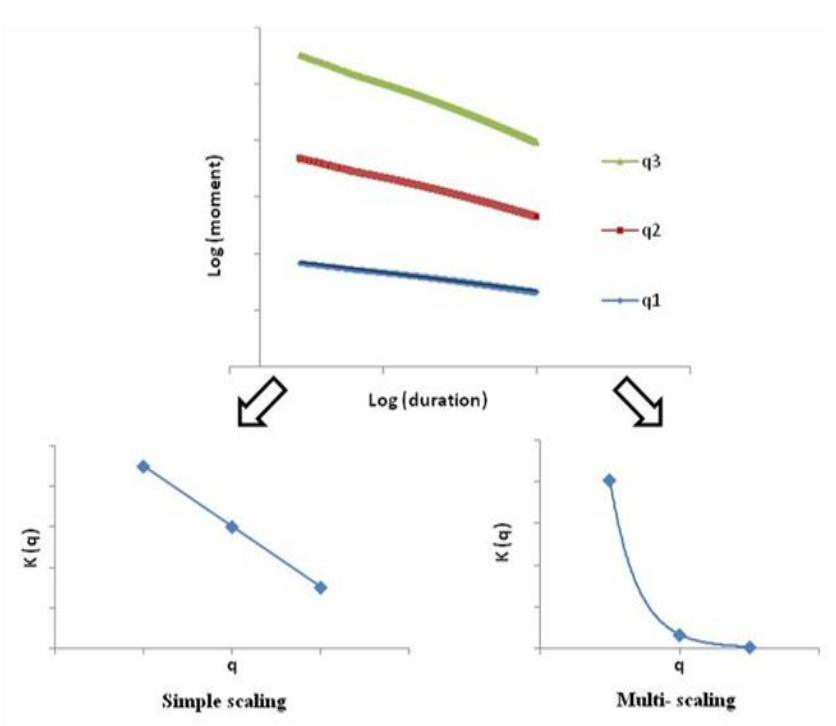

Fig. 1. Simple and multi-scaling in terms of statistical moments

\section{SCALE INVARIANCE PROPERTIES OF RAINFALLS}

The Dhaka city was selected as the study area. The recent as well as historical rainfall data for analysis herein were collected from Bangladesh Meteorological Department (BMD). Daily and 3 hourly precipitation data are available here for the year 1953 to 2013 and 2003 to 2013 respectively. The annual maximum rainfalls for different durations of Dhaka city are available in a previous study [11]. The future monthly precipitation data up to 2100 , simulated using PRECIS model, was also used from a previous study [5].

The scaling properties of extreme rainfall data of Dhaka were investigated by computing the moment for each duration and then by estimating scaling exponent $\left(H_{d}\right)$ from the slope of the linear regression relationship between log-transformed moments of extreme values and log-transformed duration for various orders of moments. Results show that the scaling exponent decreases with the order of moment and a linear relationship $\left(R^{2}=0.99\right)$ exists 
between scaling exponents and orders of moment, which implies that the property of wide sense simple scaling of rainfall intensity exists.

The obtained $H_{d}(-0.686)$ was checked by applying simple scaling theory Eq. (7) on observed annual maximum monthly, daily and 3-hourly rainfall data series for the year 2003 to 2013 . In every case $H_{d}$ was found to be very close to -0.686 (Table I) suggesting that this value can be used for development of present as well as future IDF relationships for Dhaka city.

TABLE I: THE SCALING EXPONENT, $H_{D}$ FOR DIFFERENT DOWNSCALING CONDITIONS

\begin{tabular}{ccc}
\hline \hline \multicolumn{2}{c}{ Downscaling } & $\begin{array}{c}\text { Scaling Exponent, } \\
H_{d}\end{array}$ \\
\hline \hline From & To & -0.655 \\
Monthly & Daily & -0.639 \\
Monthly & 3 hourly & -0.687 \\
Daily & 3 hourly & \\
\hline \hline
\end{tabular}

\section{DERIVATION OF IDF FOR SHORT DURATION}

All forms of the generalized IDF relationships assume that rainfall depth or intensity is inversely related to the duration of a storm raised to a power, or scale factor [12]. There are several commonly used functions found in the literature of hydrology applications [13]-[15] have modified the IDF relationship for a given return period as particular cases, using the following general empirical formula

$$
i=\frac{w}{(d+\theta)_{\eta}}
$$

where $i$ denotes the rainfall intensity for duration $d, \theta$ and $\eta$ represent non-negative coefficients. In fact, these arguments justify the formulation of the following general model for the IDF relationships:

$$
i=\frac{a(T)}{b(d)}
$$

In Equation (10), $b(d)=(d+\theta)_{\eta}$ with $\theta>0$ and $0<\eta$ $<1$, whereas $a(T)$ is completely defined by the probability distribution function of the maximum rainfall intensity. The form of Equation (10) is consistent with most IDF empirical equations estimated for many locations [16]. For example Nhat [17] established the IDF curves for precipitation in the monsoon area of Vietnam.

The random variable rainfall intensity $I(d)$ for duration $d$, has a cumulative probability distribution CDF, which is given by

$$
\operatorname{Pr}(I(d) \leq i)=F_{d}(i)=1-\frac{1}{T(i)}
$$

According to the scaling theory by Menabde [18], the scaling property in a strict sense can be written explicitly using the CDF:

$$
F_{d}(i)=F_{\lambda_{d} d}\left[\lambda_{d}^{-H_{d}} i\right]
$$

For many parametric forms, left hand side of Equation (12) may be expressed in terms of standard variant, as in

$$
F_{d}(i)=F\left[\frac{i-\mu_{d}}{\sigma_{d}}\right]
$$

where $F($.$) is a function independent of d$. Under this form, it can be deduced from Equation (12) that

$$
\begin{gathered}
\mu_{d}=\lambda_{d}{ }^{-H_{d}} \mu_{\lambda_{d} d} \\
\sigma_{d}=\lambda_{d}{ }^{-H_{d}} \sigma_{\lambda_{d} d}
\end{gathered}
$$

Substituting Equations (13), (14) and (15) into Equation (11) and investing with respect to $i$, one obtains:

$$
i_{d, T}=\frac{\mu_{\lambda_{d} d}\left(\lambda_{d} d\right)^{-H} d+\sigma_{\lambda_{d} d}\left(\lambda_{d} d\right)^{-H} d F^{-1}(1-1 / T)}{d^{-H} d}
$$

By equaling Equation (16) to the general model for IDF relationship, given by Equation (9), it is easy to verify that

$$
\begin{gathered}
\eta=-H_{d} \\
\theta=0 \\
b(d)=d^{\eta} \\
a(T)=\mu_{\lambda_{d} d}\left(\lambda_{d} d\right)^{-H_{d}}+\sigma_{\lambda_{d} d}\left(\lambda_{d} d\right)^{-H_{d}} F^{-1}(1-1 / T) \\
i_{d, T}=\frac{\mu+\sigma F^{-1}(1-1 / T)}{d^{\eta}}
\end{gathered}
$$

where $\mu=\mu_{\lambda_{d} d}\left(\lambda_{d} d\right)^{-H_{d}}$ and $\sigma=\sigma_{\lambda_{d} d}\left(\lambda_{d} d\right)^{-H_{d}}$ are termed as location parameter and scale parameter respectively.

The main objective of the study was to develop IDF relationships incorporating future climatic scenarios. As future precipitation data are available in monthly basis instead of daily, it was necessary to show that downscaling would be possible from monthly data also. That's why, at first IDF relationships are developed for observed daily and monthly annual maximum rainfall intensity by Equation (21) with $\lambda_{d}=24$ and 720 respectively. Results are plotted in Fig. 2 which shows that rainfall intensities $(\mathrm{mm} / \mathrm{hr})$ derived from both data sets almost coincide each other for different durations and return periods. This finding suggests that IDF curves could be generated using future monthly precipitation data. Hence following IDF relationships are proposed considering future as well as observed data for Dhaka city (Fig. 3):

Case 1: Observed daily annual maximum rainfall intensity of 11 years (2003-2013) yields,

$$
i_{d, T}=\frac{69.536-23.457 \ln (-\ln (1-1 / T))}{d^{0.686}}
$$

Case 2: Observed monthly annual maximum rainfall intensity of 11 years (2003-2013) yields,

$$
i_{d, T}=\frac{69.354-22.94 \ln (-\ln (1-1 / T))}{d^{0.686}}
$$

Case 3: Predicted monthly annual maximum rainfall intensity of 87 years (2014-2100) yields,

$$
i_{d, T}=\frac{175.1836-115.539 \ln (-\ln (1-1 / T))}{d^{0.686}}
$$




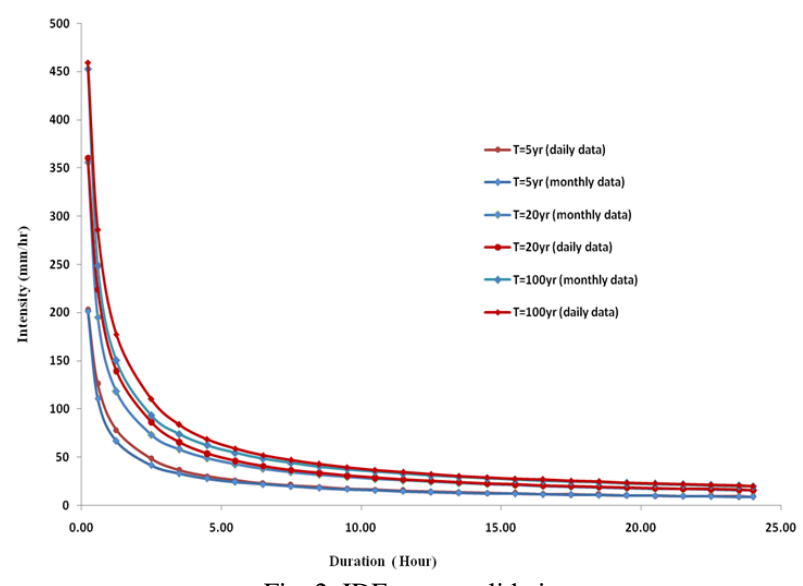

Fig. 2. IDF curve validation.

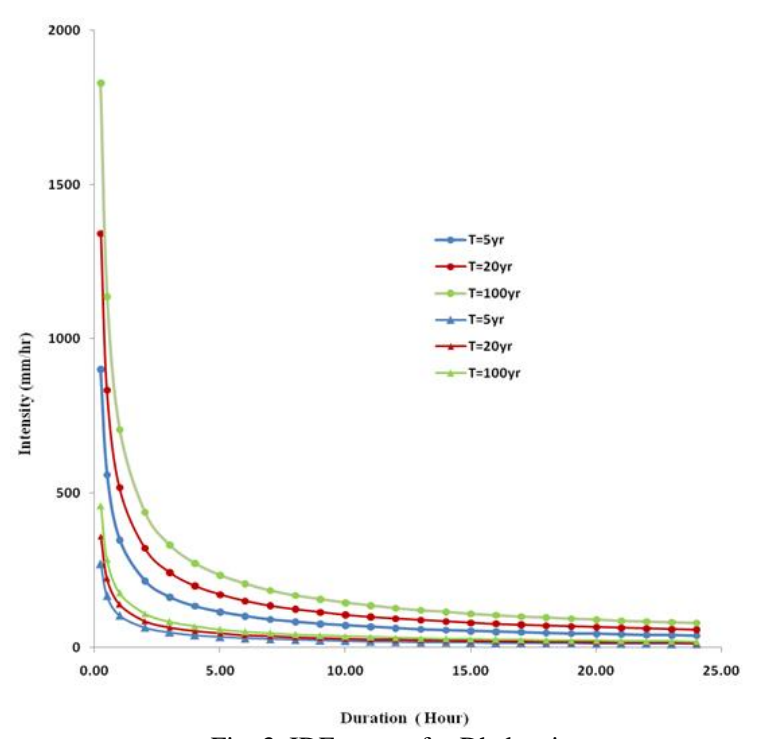

Fig. 3. IDF curves for Dhaka city.

\section{CONCLUSION}

A Based on the results of this study, it can be concluded that rainfall property in time does follow a simple scaling process for Dhaka city. The value of scaling exponent for Dhaka city derived from moment method has been validated with observed data and thus it could be used for development of present as well as future IDF relationships. IDF curves were derived from observed daily and monthly data and their similarity suggests that IDF relationships could be derived from monthly data also. This finding is important since future precipitation data of different climate models are widely available in monthly formats. Finally IDF curves are developed considering future monthly precipitation data which reflects considerably high rainfall intensity in future compare to present scenario especially for short duration rainfall event.

\section{REFERENCES}

[1] F. Ahammed, G. A. Hewa, and J. R. Argue, "Introducing Leaky-well concept for stormwater quantity control in Dhaka, Bangladesh," Appl Water Sci, vol. 3, pp. 115-123, 2013.

[2] K. Adamowski, P. Pilon, and Y. Alila, "Regional short duration rainfall intensity-frequency formula for Canada," presented at the International Workshop on Rainfall in Urban Areas, Pontresina, Switzerland, 1997.
[3] J. Bougadis and K. Adamowski, "Scaling model of a rainfall intensity-duration-frequency relationship," Hydrol Process, vol. 20, pp. 3747-3757, 2006.

[4] D. R. Maidment, Handbook of applied hydrology, McGraw-Hill, NY, 1993.

[5] M. A. Rajib, M. M. Rahman, A. K. M. S. Islam, and E. A. McBean, "Analyzing the future state of monthly precipitation pattern in Bangladesh from multi-model projections using both GCM and RCM," in Proc. the World Environmental \& Water Resources Congress, American Society of Civil Engineers (ASCE), 2011, pp. 23-26.

[6] S. B. Murshed, A. K. M. Islam, and M. S. A. Khan, "Impact of climate change on rainfall intensity in Bangladesh," International Proceedings of Water and Flood Management, Dhaka, IWFM, pp. 881-890, 8-10 January, 2011

[7] IPCC, "Climate change: The scientific basis," in Contribution of Working Group I to the Third Assessment Report of the Intergovernmental Panel on Climate Change, J. T. Houghton, Y. Ding, D. J. Griggs, M. Noguer, P. J. van der Linden, X. Dai, K. Maskell, and C. A. Johnson, Eds. Cambridge University Press, Cambridge, United Kingdom and New York, NY, USA, 2001.

[8] IPCC, "Climate Change" The physical science basis," in Contribution of Working Group I to the Fourth Assessment Report of the Intergovernmental Panel for Climate Change, S. Solomon, D. Qin, M. Manning, Z. Chen, M. Marquis, K. B. Averyt, M. Tignor, and H. L. Miller, Eds. Cambridge University Press, Cambridge, United Kingdom and New York, NY, USA, 2007.

[9] V. K. Gupta and E. Waymire, "Multiscaling properties of spatial rainfall and river flow distributions," Journal of Geophysical Research, vol. 95, pp. 1999-2009, 1990.

[10] Y. Kuzuha, Y. Komatsu, K. Tomosugi, and T. Kishii, "regional flood frequency analysis, scaling and PUB," Journal Japan Soc. Hydrol. and Water Resources, vol. 18, no. 4, pp. 441-458, 2005.

[11] K. G. Tawhid, "Causes and effects of water logging in Dhaka City, Bangladesh," M.S. thesis, Dept. of Land and Water Resource Eng., Royal Institute of Technology, KTH Stockholm, 2004.

[12] V. T. Chow, D. R. Maidment, and L. W. Mays, Applied Hydrology, McGraw-Hill, 1988.

[13] V. T. Nguyen, T. D. Nguyen and F. Ashkar, "Regional frequency analysis of extreme rainfalls," Water Sci. Technol., vol. 45, no. 2, pp. 75-81, 2002.

[14] C. L. Chen, "Rainfall intensity duration frequency formulas," Journal of Hydraulic Engineering, ASCE, vol. 109, no. 12, pp. 1603-1621, 1983.

[15] D. Koutsoyiannis and A. Manetas, "A mathematical framework for studying rainfall intensity duration frequency relationships," Journal of Hydrology, vol. 206, pp.118-135, 1998.

[16] U. C. Kothyari and R. J. Grade, "Rainfall intensity duration frequency formula for India," J. Hydr. Eng., ASCE, vol. 118, no. 2, pp. 323-336, 1992.

[17] L. M. Nhat, Y. Tachikawa, and K. Takara, "Establishment of Intensity-Duration-Frequency curves for precipitation in the monsoon area of Vietnam," Annuals of Disas. Prev. Res. Inst., Kyoto Univ., no. 49B, 2006.

[18] M. Menabde, A. Seed, and G. Pegram, "A simple scaling model for extreme rainfall," Water Resources Research, vol. 35, no.1, pp. 335-339, 1999.

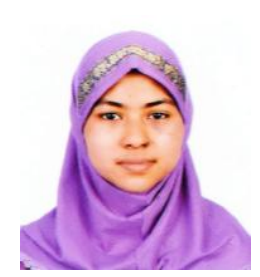

S. Afrin was born in Dinajpur, Bangladesh on 8 September, 1988. Afrin earned her B.Sc. degree in civil engineering from Bangladesh University of Engineering \& Technology (BUET), Dhaka, Bangladesh in 2012. Afrin's major field of study is environmental engineering.

She is working as a lecturer in the Department of Civil Engineering in BUET since 2012. Her research interests include air pollution, climate change, surface water modeling, drainage system, rainwater harvesting system etc.

Ms. Afrin achieved 'University Dean's List Scholarship', 'University Grant Commission Scholarship' for outstanding performance in undergraduate study. She was a member in the EIA committee of a project of Fiber@Home Ltd. named 'Nationwide Fiber Optic Network Project 'and also worked as an expert in a project of International Labor Organization (ILO) tiled 'Fire \& Electrical Safety Assessment of Existing RMG Factory Buildings in Bangladesh'. 